\title{
Acúmulo de nutrientes e resposta da alface à adubação fosfatada
}

\author{
Cristiaini Kano ${ }^{1 *}$ \\ Antonio Ismael Inácio Cardoso ${ }^{2}$ \\ Roberto Lyra Villas Boas ${ }^{3}$ \\ Embrapa Amazônia Ocidental, CP 319, CEP 69010-970, Manaus - AM, Brasil \\ ${ }^{2}$ UNESP/FCA, Departamento de Produção Vegetal. Setor Horticultura, Botucatu - SP, Brasil \\ ${ }^{3}$ UNESP/FCA, Departamento de Recursos Naturais, Setor Ciência do Solo, Botucatu - SP, Brasil \\ * Autor para correspondência \\ cristiaini.kano@cpaa.embrapa.br
}

Submetido em 01/02/2012

Aceito para publicação em 08/06/2012

\section{Resumo}

O objetivo deste trabalho foi avaliar a resposta da alface cultivar Verônica a doses de fósforo. O experimento foi desenvolvido na Fazenda Experimental São Manuel, pertencente à UNESP/FCA, Botucatu/SP, em estrutura de cultivo protegido tipo arco, no período de 25/09/2003 (semeadura) a 03/12/2003 (colheita). Utilizou-se o delineamento experimental de blocos casualizados, com cinco tratamentos $\left(0 ; 200 ; 400 ; 600\right.$ e $800 \mathrm{~kg} \cdot \mathrm{ha}^{-1}$ de $\mathrm{P}_{2} \mathrm{O}_{5}$, na forma de superfosfato triplo) e cinco repetições. As plantas foram conduzidas em vasos plásticos com capacidade para 13L contendo solo classificado como Latossolo Vermelho Distrófico Típico. Observou-se resposta quadrática para massa fresca da parte aérea da planta e área foliar, com valores máximos nas doses equivalentes a 733 e $756 \mathrm{~kg}_{\mathrm{g}}$ ha ${ }^{-1}$ de $\mathrm{P}_{2} \mathrm{O}_{5}$, respectivamente, e também para o acúmulo de potássio, cálcio, magnésio, enxofre, boro, cobre, ferro, manganês e zinco. Foram obtidos aumentos lineares com o aumento da dose de $\mathrm{P}_{2} \mathrm{O}_{5}$ aplicado para a massa seca da parte aérea, número de folhas, altura das plantas e para o acúmulo de nitrogênio e fósforo.

Palavras-chave: Fósforo; Lactuca sativa L.; Produção

\section{Abstract}

Nutrient absorption and response of lettuce to phosphorus fertilization. The objective of this study was to evaluate the response of lettuce (cultivar Verônica) to different levels of phosphorus fertilization. The experiment was conducted from 25/09/2003 (sowing) to 03/12/2003 (harvesting) at the Fazenda Experimental São Manuel, UNESP/FCA, Botucatu/SP, under protective structures. The experiment was conducted in a randomized block design, with five treatments $\left(0,200,400,600\right.$ and $800 \mathrm{~kg}^{-} \mathrm{ha}^{-1}$ of $\mathrm{P}_{2} \mathrm{O}_{5}$ in the form of triple superphosphate) and five replications. Plants were grown in 13L plastic pots containing Latossolo Vermelho Distrófico Típico. A quadratic response was observed for the fresh mass of the plant shoots and leaf area, with maximum equivalent levels of 733 and $756 \mathrm{~kg} \cdot \mathrm{ha}^{-1}$ of $\mathrm{P}_{2} \mathrm{O}_{5}$, respectively, as well as for potassium, calcium, magnesium, sulfur, boron, copper, iron, manganese and zinc accumulation. Linear increases were observed with the treatments of $\mathrm{P}_{2} \mathrm{O}_{5}$ for dry mass of the shoots, leaf number, plant height and nitrogen and phosphorus accumulation.

Key words: Lactuca sativa L.; Phosphorus; Yield 


\section{Introdução}

A alface é a hortaliça folhosa mais comercializada no Brasil, sendo fonte de vitaminas e sais minerais, destacando-se pelo elevado teor de vitamina A. A alface predominante no Brasil é do tipo crespa, com $70 \%$ do mercado (FILGUEIRA, 2003; SALA; COSTA, 2005).

Apesar da importância econômica da alface crespa, trabalhos sobre adubação fosfatada ainda são escassos e com respostas variadas, necessitando de estudos, pois a alface pode ser considerada como bastante exigente em fósforo, principalmente na fase final de seu ciclo. A deficiência deste elemento reduz o crescimento da planta, havendo má formação da cabeça, coloração verdeopaca das folhas velhas, podendo mostrar tonalidades vermelho-bronze ou púrpura (KATAYAMA, 1993).

É considerada uma planta de baixa adaptação aos solos com baixa disponibilidade de nutrientes na camada arável. Na maioria dos experimentos, essa cultura mostrou uma pronunciada resposta à adição de fósforo, sendo em solos deficientes nesse nutriente requeridas doses superiores a $600 \mathrm{~kg} \cdot$ ha $^{-1}$ de $\mathrm{P}_{2} \mathrm{O}_{5}$ para a máxima produção (SANCHEZ et al., 1990; NAGATA et al., 1992; SANCHES; EL-HOUT, 1995; MOTA et al., 2003).

Filgueira (2003) comenta que experimentalmente têm sido obtidas maiores respostas em aumento de produtividade às aplicações de fósforo e de nitrogênio em relação ao potássio, ressaltando, também, resposta ao cálcio.

No Estado de São Paulo, Raij et al. (1996) recomendam para produção de alface, a quantidade de 400; 300 e 200kg.ha- ${ }^{-1}$ de $\mathrm{P}_{2} \mathrm{O}_{5}$, quando o teor de $\mathrm{P}_{\text {resina }}$ no solo (em mg.dm ${ }^{-3}$ ) for de 0 a 25 ; de 26 a 60 e maior que 60 , respectivamente. Recomendação semelhante é indicada por Filgueira (2003) que cita a dose de até 400kg.ha- ${ }^{-1}$ de $\mathrm{P}_{2} \mathrm{O}_{5}$.

Para a cultivar Verônica, Silva et al. (2006) ao avaliarem doses de $\mathrm{P}_{2} \mathrm{O}_{5}\left(0 ; 100 ; 200 ; 400\right.$ e $\left.800 \mathrm{~kg} \cdot \mathrm{ha}^{-1}\right)$, verificaram que a média da massa fresca da parte aérea das plantas foi de 227 até o máximo de 494g.planta ${ }^{-1}$, obtido com a dose de $800 \mathrm{~kg}$.ha- ${ }^{-1}$ de $\mathrm{P}_{2} \mathrm{O}_{5}$. Já Lana et al. (2004) ao avaliarem fontes de fósforo no cultivo de alface cultivar Verônica utilizando-se em todos os tratamentos a dose de $300 \mathrm{~kg} \cdot \mathrm{ha}^{-1}$ de $\mathrm{P}_{2} \mathrm{O}_{5}$ obtiveram a máxima massa fresca da parte aérea de $123,7 \mathrm{~g}$. planta $^{-1}$.

Arruda Júnior et al. (2005) avaliaram a resposta da alface crespa 'Cacheada' a adubação fosfatada $(0 ; 3 ; 6$; 9; 20; 30 e 40mg.dm ${ }^{-3}$ ), aplicada em solo com $2 \mathrm{mg} . \mathrm{dm}^{-3}$ de $\mathrm{P}_{\text {resina, }}$, na produtividade e no teor de P na planta. Estes autores verificaram que a maior produção de massa seca da parte aérea $\left(4,35 \mathrm{~g}\right.$. planta $\left.^{-1}\right)$ e o maior teor do nutriente $\left(4,6 \mathrm{~g} \cdot \mathrm{kg}^{-1}\right)$ foram obtidos com a maior dose de P aplicada.

$\mathrm{Na}$ alface do grupo americana, Mota et al. (2003) em um solo com teor de $\mathrm{P}_{\text {resina }}$ de $12,1 \mathrm{mg} . \mathrm{dm}^{-3}$, ao avaliarem as doses de $0 ; 300 ; 600$ e $900 \mathrm{~kg} \cdot \mathrm{ha}^{-1}$ de $\mathrm{P}_{2} \mathrm{O}_{5}$ e duas fontes de fósforo, verificaram que para a fonte superfosfato simples houve regressão quadrática sendo as doses de 672 e $617 \mathrm{~kg} \cdot \mathrm{ha}^{-1}$ de $\mathrm{P}_{2} \mathrm{O}_{5}$ as que apresentaram a maior produção total $\left(1,2 \mathrm{~kg} \cdot\right.$ planta $\left.^{-1}\right)$ e comercial $\left(1,02 \mathrm{~kg}\right.$.planta $\left.{ }^{-1}\right)$, respectivamente. Para a fonte termofosfato magnesiano verificou-se aumento linear na produtividade, entretanto, mesmo para a dose mais alta, o peso total foi inferior ao observado na outra fonte.

Para cultivos comerciais é necessário realizar uma adubação mineral equilibrada, no entanto, verifica-se que a grande maioria dos produtores de hortaliças, com intuito de aumentar a produção e, principalmente pela carência de informação, utiliza fertilizantes com fórmulas NPK geralmente contendo altas concentrações de fósforo e potássio, independente dos teores desses nutrientes no solo, sem levar em consideração o tipo ou cultivar (ANDRIOLO, 1999; BONELA, 2010).

Devido à escassez de informações referentes à adubação fosfatada na cultura da alface crespa e a sua importância no mercado, o objetivo deste trabalho foi avaliar a resposta dessa alface a doses de fósforo e a extração de nutrientes.

\section{Material e Métodos}

Este trabalho foi desenvolvido na Fazenda Experimental São Manuel, localizada no município de São Manuel/SP, pertencente à Faculdade de Ciências Agronômicas (FCA) da Universidade Estadual Paulista (UNESP), Campus de Botucatu/SP, localizada à latitude 
sul de $22^{\circ} 46^{\prime}$, longitude oeste de $48^{\circ} 34^{\prime}$ e altitude de $740 \mathrm{~m}$. As plantas foram conduzidas em estrutura de cultivo protegido, tipo arco, de $20 \mathrm{~m}$ de comprimento, $7 \mathrm{~m}$ de largura e $3,8 \mathrm{~m}$ de altura, na parte mais alta e pé direito de $2,5 \mathrm{~m}$. As médias das temperaturas mínima, máxima e média obtidas no interior da estrutura foram de $18 ; 34$ e $26^{\circ} \mathrm{C}$, respectivamente.

O solo utilizado no experimento foi Latossolo Vermelho Distrófico Típico (EMBRAPA, 1999). As análises químicas do solo, avaliadas de acordo com a metodologia de Raij et al. (2001), indicaram os seguintes resultados obtidos: $\mathrm{pH}\left(\mathrm{CaCl}_{2}\right)=4,0 ; \mathrm{P}_{\text {resina }}=2 \mathrm{mg} \cdot \mathrm{dm}^{-3}$; matéria orgânica $=5 \mathrm{~g} \cdot \mathrm{dm}^{-3} ; \mathrm{V} \%=16$; e os valores de $\mathrm{H}+\mathrm{Al} ; \mathrm{K} ; \mathrm{Ca} ; \mathrm{Mg}$; SB e CTC expressos em mmol $\cdot \mathrm{dm}^{-3}$ respectivamente de: $28 ; 0,2 ; 4,0 ; 1,0 ; 5,0$ e 33 . A análise física, avaliada conforme a metodologia de Camargo et al. (1986), indicou $761 ; 199$ e $40 \mathrm{~g} \cdot \mathrm{kg}^{-1}$ de areia, argila e silte, respectivamente.

Utilizou-se o delineamento experimental de blocos casualizados com cinco tratamentos $(0 ; 200 ; 400$; 600 e $800 \mathrm{~kg}$.ha ${ }^{-1}$ de $\mathrm{P}_{2} \mathrm{O}_{5}$, na forma de superfosfato triplo, denominados de T0, T200, T400, T600 e T800, respectivamente) e cinco repetições, com seis plantas por parcela. A dose de $400 \mathrm{~kg} \cdot \mathrm{ha}^{-1}$ de $\mathrm{P}_{2} \mathrm{O}_{5}$ correspondeu à recomendada por Raij et al. (1996) para essa cultura, considerando-se o teor de $2 \mathrm{mg}$. $\mathrm{dm}^{-3}$ de $\mathrm{P}_{\text {resina }}$.

Os vasos plásticos utilizados nesse experimento possuíam altura de $25 \mathrm{~cm}$ e diâmetro de $28 \mathrm{~cm}$, com capacidade de $13 \mathrm{~L}$. As quantidades de $\mathrm{P}_{2} \mathrm{O}_{5}$ colocadas em cada tratamento corresponderam ao equivalente a 0 1,$3 ; 2,6 ; 3,9$ e 5,2g por vaso para T0, T200, T400, T600 e T800, respectivamente.

A aplicação de calcário em todo o volume do solo foi realizada 30 dias antes do transplante das mudas, utilizando-se calcário de alta reatividade com PRNT de $90 \%$, visando atingir a saturação por bases a $80 \%$, conforme a recomendação sugerida por Raij et al. (1996).

A adubação de plantio correspondeu ao fornecimento em cada vaso de $0,26 \mathrm{~g}$ de $\mathrm{N}$ (na forma de sulfato de amônio), 1,6g de $\mathrm{K}_{2} \mathrm{O}$ (na forma de cloreto de potássio) e $500 \mathrm{~g}$ de Biomix $^{\circledR}$ (como fonte de matéria orgânica). Os adubos e o Biomix ${ }^{\circledR}$ foram misturados uniformemente ao solo de todo o vaso.
A análise química do Biomix ${ }^{\circledR}$ indicou valor de $\mathrm{pH}$ de 7,7 e os valores de $\mathrm{MO} ; \mathrm{N} ; \mathrm{P}_{2} \mathrm{O}_{5} ; \mathrm{K}_{2} \mathrm{O} ; \mathrm{Ca} ; \mathrm{Mg}$ e de S expressos em \% foram de: $53 ; 1,30 ; 0,90 ; 0,47 ; 6,80$; 0,25 e 0,34 , respectivamente. A relação $\mathrm{C} / \mathrm{N}$ foi de $23 / 1$ e a umidade de $60 \%$.

Todo fósforo foi fornecido no plantio. A adubação de cobertura com nitrogênio foi feita com nitrato de cálcio $(0,19 \mathrm{~g}$ de $\mathrm{N}$ por vaso por aplicação $)$ e realizada aos $8 ; 15 \mathrm{e}$ 21 dias após o transplante (DAT), conforme recomendação de Raij et al. (1996) para a produção de alface.

Foi utilizada a cultivar de alface crespa 'Verônica' e a semeadura foi realizada no dia 25/09/2003 em bandejas de poliestireno expandido de 128 células, contendo substrato comercial para hortaliças. Foram colocadas duas sementes por célula, com posterior desbaste para uma planta por célula.

As mudas foram transplantadas em 30/10/2003 e foi cultivada uma planta por vaso, dispondo-se os vasos em linhas no sentido longitudinal da estufa, sendo a planta localizada em cada extremidade da parcela usada como bordadura.

O controle fitossanitário foi realizado com deltrametrina para o controle de pulgão, sempre que necessário e a irrigação foi realizada diariamente por meio de gotejadores instalados individualmente nos vasos até verificar o início do escorrimento de água no fundo dos mesmos.

A colheita foi realizada aos 34 DAT (03/12/2003), quando as plantas atingiram o ponto de colheita, determinando-se nesse dia a altura das plantas, massa fresca da parte aérea das plantas, número de folhas e área foliar. A massa seca da parte aérea das plantas foi obtida após lavagem com água destilada e, depois, secagem das plantas em estufa de circulação forçada de ar a $65^{\circ} \mathrm{C}$ até atingirem massa constante e as análises químicas das plantas foram realizadas na parte aérea conforme metodologia citada por Malavolta et al. (1997), sendo os teores de macronutrientes $\left(\mathrm{g}_{\mathrm{kg}} \mathrm{kg}^{-1}\right)$ e de micronutrientes $\left(\mathrm{mg} . \mathrm{kg}^{-1}\right)$ multiplicados pela massa seca da parte aérea da planta a fim de estabelecer a quantidade de cada nutriente acumulado por planta, obtendo-se os dados de acúmulo de macronutrientes em mg.planta ${ }^{-1}$ e os de micronutrientes em $\mu$ g.planta ${ }^{-1}$. 
A altura foi obtida medindo-se a distância entre a superfície do solo e a parte mais alta da planta e a massa fresca da parte aérea foi obtida logo após a colheita. Para o número de folhas consideraram-se todas as folhas da planta e a área foliar foi obtida com o integrador Li-Cor, modelo LI-3100.

Os resultados obtidos foram submetidos à análise de variância e em caso de efeito significativo, de acordo com o teste $\mathrm{F}$ para tratamentos, foi realizada a análise de regressão para verificar o efeito de doses de $\mathrm{P}_{2} \mathrm{O}_{5}$ nas características avaliadas através do software Sisvar (FERREIRA, 2000).

\section{Resultados e Discussão}

As variáveis analisadas apresentaram diferenças significativas pelo teste $\mathrm{F}$, demonstrando que as doses de $\mathrm{P}_{2} \mathrm{O}_{5}$ influenciaram todas as características vegetativas e acúmulo dos nutrientes avaliados (Figuras 1; 2 e 3).

A massa fresca da parte aérea das plantas (produção) e a área foliar ajustaram-se estatisticamente ao modelo

FIGURA 1: Produção (massa fresca da parte aérea) por planta (a), área foliar (b), massa seca da parte aérea (c), número de folhas por planta (d) e altura das plantas (e) de alface crespa 'Verônica' em função das doses de $\mathrm{P}_{2} \mathrm{O}_{5}$. Média de cinco repetições em cada ponto. ** Significativo a $1 \%$ de probabilidade, pelo teste $\mathrm{F}$.

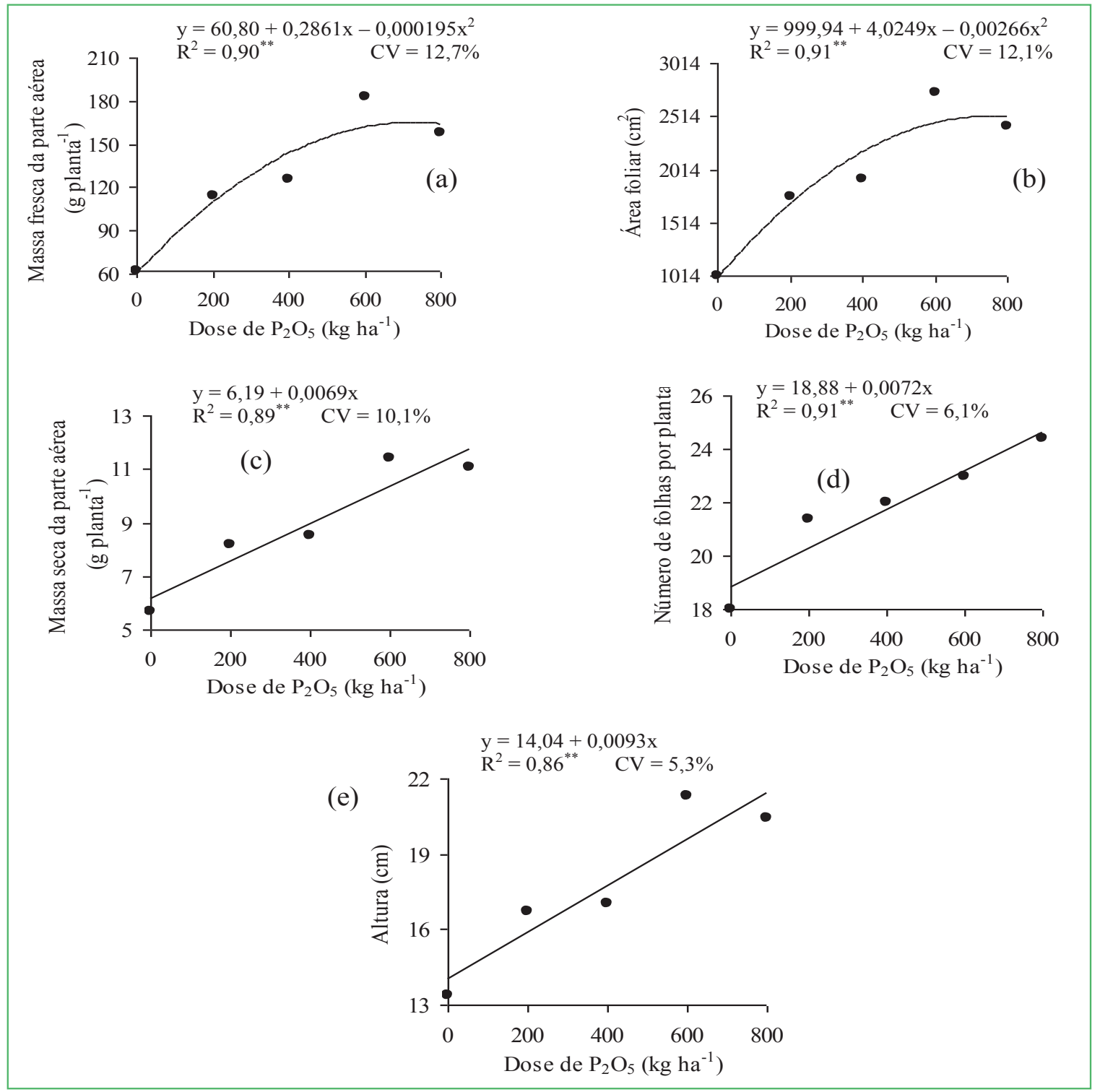


quadrático, com valores máximos de 166g.planta ${ }^{-1} \mathrm{e}$ $2522 \mathrm{~cm}^{2}$ obtidos nas doses equivalentes a 733 e $756 \mathrm{~kg}$. ha $^{-1}$ de $\mathrm{P}_{2} \mathrm{O}_{5}$, respectivamente (Figura 1a e 1b).

A massa fresca da parte aérea das plantas obtida foi considerada comercial ( $\geq 100 \mathrm{~g}$ ) e com valor superior ao obtido em alface crespa por Santos et al. (2005) e ao maior valor obtido por Viana e Vasconcelos (2008) que foram de 104,2 e 123,8g.planta-1 ${ }^{-1}$ para a cultivar Verônica e Vera, respectivamente. $\mathrm{O}$ aumento da massa fresca da parte aérea dessa cultivar com o aumento de doses de $\mathrm{P}_{2} \mathrm{O}_{5}$ também foi verificado por Silva et al. (2006).

A área foliar obtida nesse trabalho $\left(2743 \mathrm{~cm}^{2}\right)$ mesmo sendo inferior a obtida por Feltrim et al. (2009) que foi de $4872 \mathrm{~cm}^{2}$ para a cultivar Verônica cultivada no campo, demonstrou resposta as doses de fósforo avaliadas.

A massa seca da parte aérea, número de folhas por planta e altura das plantas ajustaram-se estatisticamente ao modelo linear, obtendo-se aumento nesses valores com o aumento da dose de $\mathrm{P}_{2} \mathrm{O}_{5}$ (Figura 1c, 1d e 1e).

Para a massa seca da parte aérea (Figura 1c), obtevese um incremento de 0,7g.planta ${ }^{-1}$ para cada $100 \mathrm{~kg} \mathrm{P}_{2} \mathrm{O}_{5}$ aplicado. A máxima massa seca da parte aérea da planta obtida nesse experimento foi próxima de $11 \mathrm{~g}$ planta $^{-1}$, valor superior ao obtido por Arruda Júnior et al. (2005), que também avaliaram doses crescentes de fósforo para a cultivar crespa 'Cacheada' e obtiveram a máxima produção de massa seca da parte aérea $\left(4,35 \mathrm{~g}\right.$. planta $\left.^{-1}\right)$ na maior dose (40mg. $\left.\mathrm{dm}^{-3}\right)$. Para a cultivar Verônica, Beninni et al. (2005), Cézar (2005), Saldanha et al. (2005), Grangeiro et al. (2006) e Coutinho (2008) obtiveram massa seca da parte aérea da planta próximo de 5; 6,4; 8,1; 9,8 e 12,11g. planta $^{-1}$, respectivamente. $\mathrm{O}$ incremento na produção da massa seca da parte aérea das plantas de alface cultivadas em vasos em função do aumento das doses de $\mathrm{P}$ também foi verificado por Coutinho (2008) para as cultivares de alface Verônica, Regina e Lucy Brown.

O número de folhas por planta apresentou um aumento de aproximadamente uma folha por planta para cada 100kg $\mathrm{P}_{2} \mathrm{O}_{5}$ aplicado (Figura 1d), e variou de 18 (T0) a 24 folhas (T800), com uma média de 21 folhas por planta, valor superior ao obtido por Santos et al. (2005) para essa mesma cultivar, que obtiveram uma média de 15 folhas por planta.
Para cada 100kg de $\mathrm{P}_{2} \mathrm{O}_{5}$ aplicado obteve-se um aumento de $0,9 \mathrm{~cm}$ na altura da planta (Figura 1e). Os valores de altura das plantas variaram de 13 a $21 \mathrm{~cm}$, com uma média de $17 \mathrm{~cm}$, valor superior ao obtido por Santos et al. (2005) para a cultivar Verônica que obtiveram altura de $13 \mathrm{~cm}$. Já Silva et al. (2006) verificaram que a altura das plantas de alface crespa cultivar Verônica não foi influenciada pelas doses de $\mathrm{P}_{2} \mathrm{O}_{5}$ que variaram de 0 a $800 \mathrm{~kg} \cdot \mathrm{ha}^{-1}$.

Houve resposta linear para o acúmulo de nitrogênio (Figura 2a) e fósforo (Figura 2b), demonstrando aumento do acúmulo desses nutrientes com o aumento da dose de $\mathrm{P}_{2} \mathrm{O}_{5}$ fornecido, com acúmulos máximos de 361,95 e 41,68mg.planta ${ }^{-1}$ de $\mathrm{N}$ e $\mathrm{P}$, respectivamente. Para o acúmulo de K (Figura 2c), Ca (Figura 2d), Mg (2e), S (Figura 2f), B (Figura 3a), Cu (Figura 3b), Fe (Figura 3c), Mn (Figura 3d) e Zn (Figura 3e) obteve-se resposta quadrática com o aumento da dose de $\mathrm{P}_{2} \mathrm{O}_{5}$ aplicado.

Grant et al. (2001) comenta que com menor área foliar, causada pela deficiência de fósforo, há menor captação da radiação solar e, consequentemente, menos carboidratos, afetando a subsequente emergência das raízes e reduzindo a capacidade de absorção de fósforo pela planta, o que explicaria o menor acúmulo encontrado na menor dose de $\mathrm{P}_{2} \mathrm{O}_{5}$ avaliada.

A ordem decrescente do acúmulo máximo dos macronutrientes, em mg.planta ${ }^{-1}$, foi: $\mathrm{K}(527)>\mathrm{N}$ (362) $>\mathrm{Ca}(151)>\mathrm{P}(42)>\mathrm{Mg}(36)>\mathrm{S}$ (14), e a dos micronutrientes, em $\mu$ g.planta ${ }^{-1}$, foi: $\mathrm{Fe}(1381)>\mathrm{Mn}$ (687) $>\mathrm{Zn}(208) \sim \mathrm{B}(204)>\mathrm{Cu}$ (73). Ordem semelhante foi observada por Grangeiro et al. (2006), também com alface 'Verônica', com acúmulo por planta de $330 \mathrm{mg}$ de $\mathrm{K}$; 240mg de N; 110mg de P; 100mg de $\mathrm{Mg}$ e 50mg de Ca. Quanto aos valores, apenas o acúmulo de $\mathrm{Mg}$ foi menor na presente pesquisa. A massa seca da parte aérea obtida no ponto de colheita (27 DAT) por estes autores foi de $6,4 \mathrm{~g}$. planta $^{-1}$. Já Beninni et al. (2005), que estudaram o acúmulo de macronutrientes em alface cultivar Verônica cultivada em sistema convencional, obtiveram ordem semelhante, apenas com a inversão do $\mathrm{S}$ e do $\mathrm{Mg}$, com os seguintes valores, em mg planta ${ }^{-1}$ : K (766) $>\mathrm{N}(372)>\mathrm{Ca}(119)>\mathrm{P}$ (78) $>\mathrm{S}(38)>\mathrm{Mg}(30)$. A massa fresca e a massa seca da parte aérea encontrada por esses autores foram de 268,92 e 9,78g.planta ${ }^{-1}$, respectivamente. 
FIGURA 2: Acúmulo de nitrogênio (a), fósforo (b), potássio (c), cálcio (d), magnésio (e) e de enxofre (f), em alface crespa 'Verônica’ em função das doses de $\mathrm{P}_{2} \mathrm{O}_{5}$. Média de cinco repetições em cada ponto. ** e * Significativo a 1 e $5 \%$ de probabilidade, pelo teste $\mathrm{F}$.

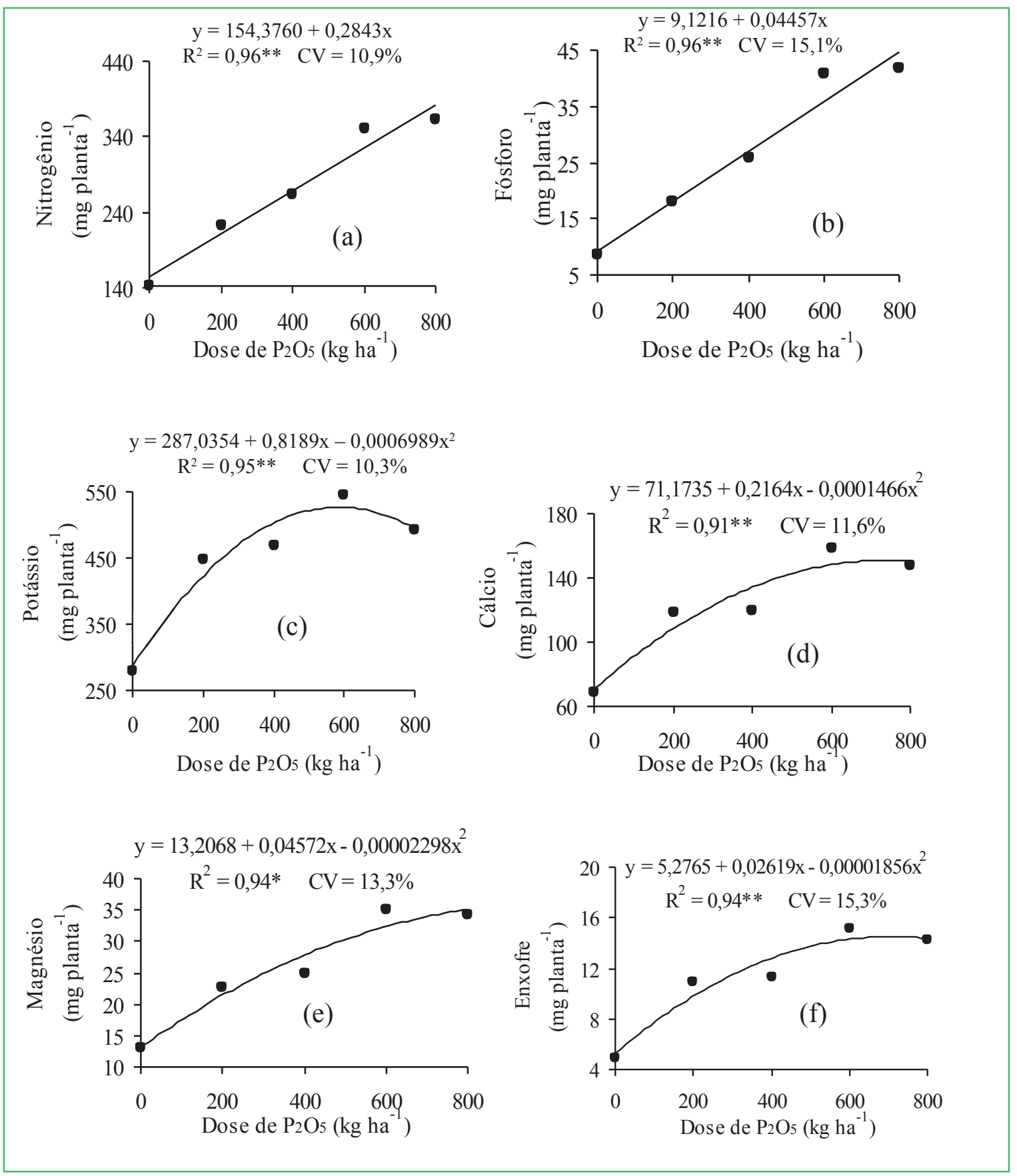


FIGURA 3: Acúmulo de boro (a), cobre (b), ferro (c), manganês (d) e de zinco (e), em alface crespa 'Verônica' em função das doses de $\mathrm{P}_{2} \mathrm{O}_{5}$. Média de cinco repetições em cada ponto. ** e * Significativo a 1 e $5 \%$ de probabilidade, pelo teste $\mathrm{F}$.

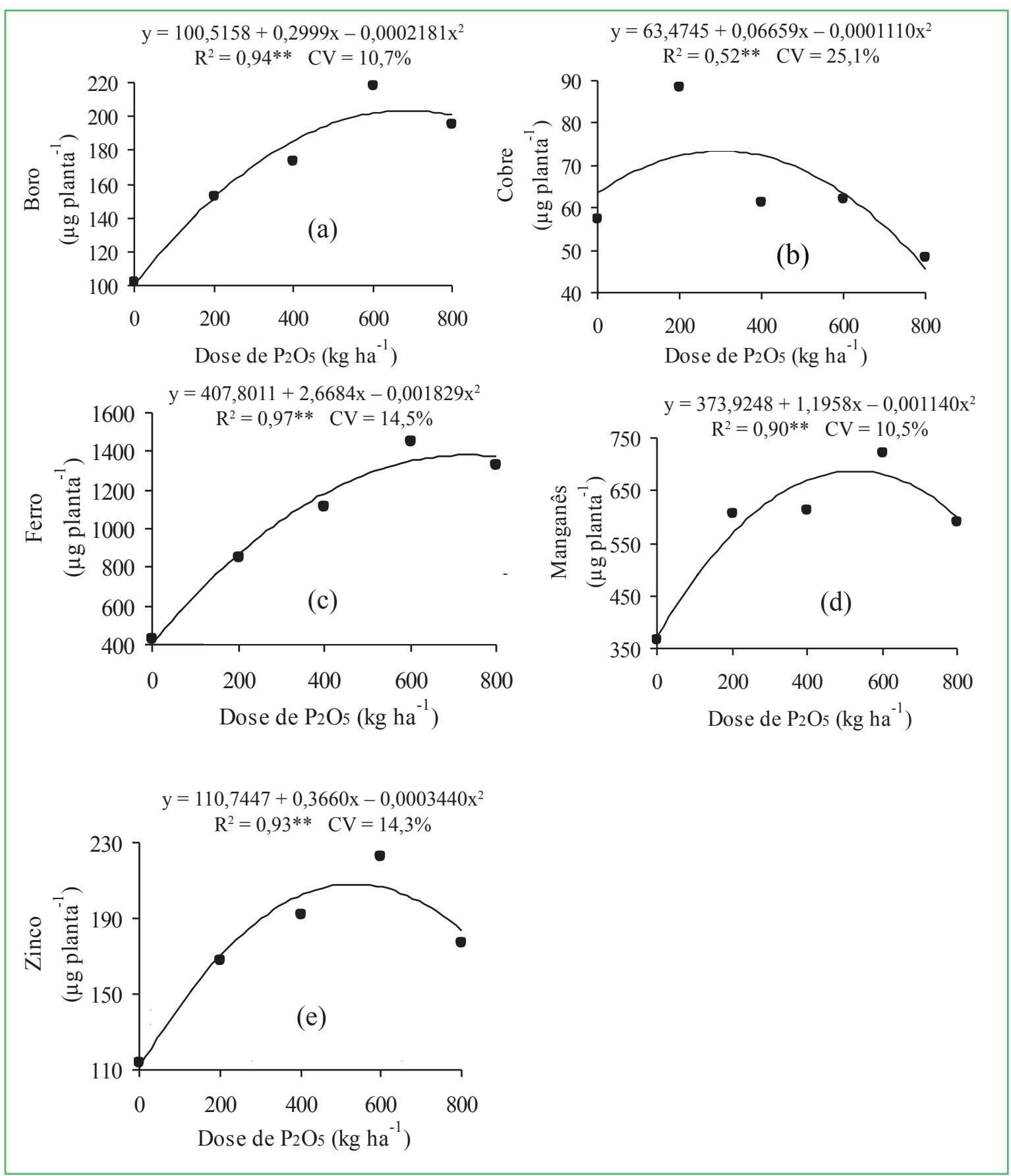


A maior absorção de ferro e manganês, também foi observado por Furlani (1997) na alface cultivar Verônica que obteve a seguinte ordem decrescente do acúmulo: ferro $>$ manganês $>$ boro $>$ zinco $>$ cobre e por Agapito et al. (1997) em quatro cultivares de alface que foi de: ferro $>$ manganês $>$ zinco $>$ cobre.

Realizou-se a análise química das plantas de todos os tratamentos na fase de diagnose foliar com o objetivo de avaliar o estado nutricional (Tabela 1). Conforme Raij et al. (1996), os teores foliares de nitrogênio e de potássio foram adequados para todos os tratamentos, pois estiveram na faixa de 30 a $50 \mathrm{~g} \cdot \mathrm{kg}^{-1}$ de $\mathrm{N}$ e 50 a $80 \mathrm{~g} . \mathrm{kg}^{-1}$ de K. Os teores de fósforo foram adequados apenas para o T400, T600 e T800, ressaltando-se que o T400 (400kg.ha- ${ }^{-1}$ de $\mathrm{P}_{2} \mathrm{O}_{5}$ ) é a quantidade recomendada por Raij et al. (1996), para o teor de P presente no solo utilizado no experimento, para a planta de alface para consumo de folhas, pois recomenda-se que o teor esteja na faixa de 4 a $7 \mathrm{~g} \mathrm{~kg}^{-1}$ de P. Os teores de cálcio foram adequados apenas para o T200, T600 e T800, pois foram os tratamentos que tiveram teor na faixa de 15 a $25 \mathrm{~g}$. $\mathrm{kg}^{-1}$ de Ca. Quanto ao magnésio, todos os tratamentos tiveram teor abaixo da faixa considerada adequada (4 a $\left.6 \mathrm{~g} \cdot \mathrm{kg}^{-1}\right)$. Os teores de enxofre foram adequados para todos os tratamentos, pois apresentaram teor de 1,5 a 2,5g. $\mathrm{kg}^{-1}$ de S, exceto para o T0.

TABELA 1: Teor foliar de macronutrientes contidos na folha diagnóstica da planta de alface (coletada aos 20 dias após o transplante). Botucatu/SP, UNESP/FCA, 2003.

\begin{tabular}{|c|c|c|c|c|c|c|}
\hline $\begin{array}{c}\text { Tratamento } \\
\left(\text { kg.ha }^{-1}{\left.\text { de } \mathrm{P}_{2} \mathrm{O}_{5}\right)}\right)\end{array}$ & \multicolumn{6}{|c|}{ g. $\mathrm{kg}^{-1}$} \\
\hline T0 (0) & 32 & 2,1 & 57 & 13 & 3,1 & 1,3 \\
\hline T200 (200) & 35 & 3,3 & 59 & 15 & 3,5 & 2,0 \\
\hline T400 (400) & 36 & 4,0 & 63 & 14 & 3,4 & 2,1 \\
\hline T600 (600) & 37 & 4,8 & 64 & 15 & 3,6 & 2,1 \\
\hline T800 (800) & 37 & 5,0 & 62 & 16 & 3,6 & 1,9 \\
\hline
\end{tabular}

Média de cinco repetições por tratamento.

Em relação aos micronutrientes (Tabela 2), os teores de boro e de zinco estiveram abaixo da faixa considerada adequada (30 a 60 e 30 a $100 \mathrm{mg} \mathrm{kg}^{-1}$ para boro e zinco respectivamente). Os teores de cobre foram adequados (estiveram entre 7 a $20 \mathrm{mg} \cdot \mathrm{kg}^{-1}$ ) exceto para o T0. Quanto ao ferro, os teores foram adequados para o T0, T400 e T800, pois o T200 e T600 apresentaram teores um pouco acima da faixa adequada (50 a $150 \mathrm{mg}$. $\left.\mathrm{kg}^{-1}\right)$. Os teores de manganês foram adequados para todos os tratamentos (estiveram dentro de 30 a $150 \mathrm{mg} \cdot \mathrm{kg}^{-1}$ ).

TABELA 2: Teor foliar de micronutrientes contidos na folha diagnóstica da planta de alface (coletada aos 20 dias após o transplante). Botucatu/SP, UNESP/FCA, 2003.

\begin{tabular}{cccccc}
$\begin{array}{c}\text { Tratamento } \\
\text { (kg.ha }^{-1} \mathbf{d e ~}_{\mathbf{2}} \mathbf{O}_{\mathbf{5}} \text { ) }\end{array}$ & B & $\mathbf{C u}$ & $\begin{array}{c}\text { Fe } \\
\mathrm{mg} \cdot \mathrm{kg}^{-1}\end{array}$ & $\mathbf{M n}$ & $\mathbf{Z n}$ \\
\hline $\mathrm{T} 0(0)$ & 25 & 1,5 & 142 & 76 & 23 \\
$\mathrm{~T} 200(200)$ & 25 & 11,5 & 167 & 67 & 23 \\
$\mathrm{~T} 400(400)$ & 25 & 7,7 & 122 & 60 & 23 \\
$\mathrm{~T} 600(600)$ & 24 & 10,6 & 153 & 66 & 24 \\
$\mathrm{~T} 800(800)$ & 23 & 11,2 & 143 & 59 & 23 \\
\hline
\end{tabular}

Média de cinco repetições por tratamento.

Apesar de cada um dos autores citados terem realizado as pesquisas em diferentes condições ambientais, percebe-se que a ordem e a demanda pelos nutrientes em alface crespa não são muito contrastantes e podem ajudar na validação de recomendações de adubação para a alface crespa.

A dose ótima de fósforo encontrada $\left(733 \mathrm{~kg} \cdot \mathrm{ha}^{-1} \mathrm{de}\right.$ $\mathrm{P}_{2} \mathrm{O}_{5}$ ) foi praticamente quase o dobro da recomendação de adubação para a cultura da alface, para esse tipo de solo, mas, ressalta-se que como esse trabalho foi conduzido em vasos, apenas tem-se o indicativo para futuros trabalhos.

Conclui-se que a máxima produção de alface foi obtida com a dose equivalente a $733 \mathrm{~kg}$.ha- ${ }^{-1}$ de $\mathrm{P}_{2} \mathrm{O}_{5}$ e a ordem decrescente de acúmulo de nutrientes nas plantas foi: $\mathrm{K}>\mathrm{N}>\mathrm{Ca}>\mathrm{P}>\mathrm{Mg}>\mathrm{S}>\mathrm{Fe}>\mathrm{Mn}>\mathrm{Zn} \sim \mathrm{B}>\mathrm{Cu}$. 


\section{Referências}

AGAPITO, P. J. A.; CONTRERAS, N. U.; PINZON, H.; LAVERDE, P. H. Nutrient absorption in four lettuce, Lactuca sativa L., source materials. Agronomia Colombiana, Bogotá, v. 14, n. 1, p. 28-36, 1997.

ANDRIOLO, J. L. Fisiologia das culturas protegidas. Santa Maria: UFSM, 1999. 142 p.

ARRUDA JÚNIOR, S. J. de; MELO, E. E. C. de; SILVA, M. O.; SOUSA, C. E. S. de; FREIRE, M. B. G. S. Produtividade e teor de $P$ de plantas de alface em função de diferentes doses de fósforo no solo. Horticultura Brasileira, Brasília, v. 23, n. 2, Suplemento, Resumos, 2005. CD-ROM.

BENINNI, E. R. Y.; TAKAHASHI, H. W.; NEVES, C. S. V. J. Concentração e acúmulo de macronutrientes em alface cultivada em sistemas hidropônico e convencional. Semina, Londrina, v. 26, n. 3, p. 273-282, 2005.

BONELA, G. D. Adubação fosfatada e potássica para alface em Latossolo com teores altos de $\mathbf{P}$ e $\mathbf{K}$ disponíveis. 2010. 55 f. Dissertação (Mestrado em Agronomia) - Universidade Estadual Paulista, Jaboticabal. 2010.

CAMARGO, O. A.; MONIZ, A. C.; JORGE, J. M. A. S. Métodos de análises químicas, mineralógicas e física de solos do Instituto Agronômico de Campinas. Boletim Técnico Instituto Agronômico, Campinas, n. 106, p. 1-94, 1986.

CÉZAR, V. R. S. Efeito do processo de compostagem sobre a solubilização e a eficiência agronômica de diferentes fontes de fósforo. 2005. 66 f. Tese (Doutorado em Agronomia) - Universidade Estadual Paulista, Botucatu. 2005.

COUTINHO, E. L. M. Adubação fosfatada em cultivares de alface cultivada em solos deficientes. Nucleus, Ituverava, v. 5, n. 2, p. 279-288, 2008.

EMBRAPA - EMPRESA BRASILEIRA DE PESQUISA AGROPECUÁRIA. Sistema brasileiro de classificação de solos. 1 ed. Brasília: Embrapa, 1999. 412 p.

FELTRIM, A. L.; CECÍlio FILHO, A. B.; REZENDE, B. L. A.; BRANCO, R. B. F. Produção de alface crespa em solo e em hidroponia, no inverno e verão, em Jaboticabal-SP. Científica, Jaboticabal, v. 37, n. 01, p. 9-15, 2009.

FERREIRA, D. F. Manual do sistema Sisvar para análises estatísticas. Lavras: UFLA, 2000. 66 p.

FILGUEIRA, F. A. R. Asteráceas - Alface e outras hortaliças herbáceas. In: FILGUEIRA, F. A. R. (Ed.). Novo manual de olericultura: agrotecnologia moderna na produção e comercialização de hortaliças. Cap. 17. 2. ed. Viçosa: UFV, 2003. p. 289-295.

FURLANI, P. R. Instruções para o cultivo de hortaliças de folhas pela técnica de Hidroponia NFT. Campinas: Instituto Agronômico, 1998, 30 p. (Boletim técnico, 168).

GRANGEIRO, L. C.; KAMARGO, R. C.; MEDEIROS, M. A. de.; SALVIANO, A. M.; NEGREIROS, M. Z. de; BEZERRA NETO, F.; OLIVEIRA, S. L. Acúmulo de nutrientes por três cultivares de alface cultivadas em condições do semiárido. Horticultura Brasileira, Brasília, v. 24, n. 2, p. 190-194, 2006.

GRANT, C. A.; FLATEN, D. N.; TOMASIEWICZ, D. J.; SHEPPARD, S. C. A importância do fósforo no desenvolvimento inicial da planta. Informações Agronômicas, Piracicaba, n. 95, p. $1-5,2001$.

KATAYAMA, M. Nutrição e adubação de alface, chicória e almeirão. In: FERREIRA, M. E.; CASTELLANE, P. D.; CRUZ, M. C. P. (Ed.). Nutrição e adubação de hortaliças. Piracicaba: Potafós, 1993. p. 141-148.

LANA, R. M. Q.; ZANÃO JÚNIOR, L. A.; LUZ, J. M. Q.; SILVA, J. C.da. Produção da alface em função do uso de diferentes fontes de fósforo em solo de Cerrado. Horticultura Brasileira, Brasília, v. 22, n. 3, p. 525-528, 2004.

MALAVOLTA, E.; VITTI, G. C.; OLIVEIRA, S. A. de. Avaliação do estado nutricional das plantas princípios e aplicações. 2. ed. Piracicaba: Potafós, 1997. 319 p.

MOTA, J. H.; YURI, J. E.; RESENDE, G. M.; OLIVEIRA, C. M.; SOUZA, R. J.; FREITAS, S. A. C.; RODRIGUES JÚNIOR, J. C. Produção de alface americana em função da aplicação de doses e fontes de fósforo. Horticultura Brasileira, Brasília, v. 21, n. 4, p. 620-622, 2003.

NAGATA, R. T.; SANCHEZ, C. A.; COALE, F. J. Crisphead lettuce cultivar response to fertilizer phosphorus. Journal of American Society for Horticultural Science, Alexandria, v. 117, n. 5, p. 717 720, 1992.

RAIJ, B. Van; CANTARELLA, H.; QUAGGIO, J. A.; FURLANI, A. M. C. Recomendações de adubação e calagem para o Estado de São Paulo. Campinas: Instituto Agronômico \& Fundação IAC, 1996. 285 p.

RAIJ, B. V.; ANDRADE, J. C.; CANTARELLA, H.; QUAGGIO, J. A. Análise química para avaliação da fertilidade de solos tropicais. Campinas: Instituto Agronômico, 2001. 285 p.

SALA, F. C.; COSTA, C. P. 'Piraroxa': cultivar de alface crespa de cor vermelha intensa. Horticultura Brasileira, Brasília, v. 23, n. 1, p. 158-159, 2005.

SALDANHA, T. R. F. da. C.; NEGREIROS, M. Z. de.; BEZERRA NETO, F.; GUIMARÃES, R. A. S. Cultivares de alface crespa em sistemas solteiro e consorciado com cenoura. Caatinga, Mossoró, v. 18, p. 176-184, 2005.

SANCHEZ, C. A.; EL-HOUT, N. M. Response of diverse lettuce types to fertilizer phosphorus. HortScience, Alexandria, v. 30, n. 3, p. 528-531, 1995.

SANCHEZ, C. A.; SWANSON, S.; PORTER, P. S. Banding phosphorus to improve fertilizer use efficiency of lettuce. Journal of American Society for Horticultural Science, Alexandria, v. 115, p. 581-584, 1990.

SANTOS, F. N.; ARAÚJO, J. R. G.; COSTA, E. M. R. C.; COSTA, E. P. B.; SILVA, J. C. B.; SILVA, J. R.; FREITAS, L. M.; VELOSO, T. R. G. Avaliação de cultivares de alface sob as condições de cultivos a ambiente protegido e a campo. Horticultura Brasileira, Brasília, v. 23, n. 2, Suplemento, Resumos, 2005. CD-ROM.

SILVA, N. F. da.; SILVA, D. E. da.; TEIXEIRA, W. S.; SONNENBERG, P. E. Crescimento e produção de cultivares de alface em função de doses de fósforo. Horticultura Brasileira, Brasília, v. 24, n. 1, Suplemento, Resumos, 2006. CD-ROM.

VIANA, E. M.; VASCONCELOS, A. C. F. Produção de alface adubada com termofosfato e adubos orgânicos. Revista Ciência Agronômica, Fortaleza, v. 39, n. 2, p. 217-224, 2008. 